\title{
Comparison of wheat simulation models under climate change. II. Application of climate change scenarios
}

\author{
M. A. Semenov ${ }^{1, *}$, J. Wolf ${ }^{2}$, L. G. Evans ${ }^{1}$, H. Eckersten ${ }^{3}$, A. Iglesias ${ }^{4}$ \\ 'IACR-Long Ashton Research Station, Dept of Agricultural Sciences, University of Bristol, Bristol BS18 9AF, United Kingdom \\ ${ }^{2}$ Dept of Theoretical Production Ecology, Wageningen Agricultural University, PO Box 430, Wageningen 6700 AK, \\ The Netherlands \\ ${ }^{3}$ Dept of Soil Sciences, Swedish Agricultural University, PO Box 7014, S-75007 Uppsala, Sweden \\ ${ }^{4}$ Dept Sistemas Forestales, CIT-INIA, E-28040 Madrid, Spain
}

\begin{abstract}
A comparison of the performance of 5 wheat models (AFRCWHEAT2, CERES, NWHEAT, SIRIUS and SOILN) was carried out for 2 sites in Europe: Rothamsted, UK, and Seville, Spain. The aims of this study were (1) to compare predictions of wheat models for climate change scenarios, and (2) to investigate the effects of changes in climatic variability in climate change scenarios on model predictions. Simulations were run for climate change scenarios derived from a number of $2 \times \mathrm{CO}_{2}$ equilibrium and transient GCM (global circulation model) experiments. For most climate change scenarios the model results were broadly similar. Where results differed, much of the difference could be explained by model sensitivity to climate and differences in initial conditions. Transient scenarios without changes in climatic variability usually resulted in large yield increases for Rothamsted and in nil to large yield increases for Seville. Incorporation of changed climatic variability in the transient scenario had a more profound effect on grain yield and resulted in a substantial decrease in mean yield with a strong increase in yield variation at Seville. This was associated with the changes in the duration of dry spells and a redistribution of precipitation over the vegetation period. The results show that future studies of the effect of climate change on crop yields must consider changes in climatic variability as well as changes in mean climate.
\end{abstract}

KEY WORDS: Simulation wheat models - Climate change Climatic variability $\cdot$ Inter-model comparison

\section{INTRODUCTION}

A comparison of the performance of 5 wheat models under climate change conditions was carried out for 2 sites in Europe with considerably different climatic conditions. The wheat models were: AFRCWHEAT2 (Porter 1984, 1993, Weir et al. 1984); CERES (Ritchie \& Otter 1985, Godwin et al. 1990); NWHEAT (Groot 1987, 1993); SIRIUS (Jamieson \& Wilson 1988, Jamieson et al. in press); and SOILN (Johnsson et al. 1987, Eckersten \& Jansson 1991, Eckersten et al. 1994).

\footnotetext{
•E-mail: mikhail.semenov@bbsrc.ac.uk
}

The models were first calibrated against field experiments from both sites. Subsequently, the sensitivity of the model results to stepwise changes in means and variances of climatic variables was determined. Results from these calibration and sensitivity analyses were described by Wolf et al. (1996, this issue). The aims of this paper are (1) to compare predictions of wheat models for climate change scenarios, derived from a number of general circulation models (GCMs), and (2) to investigate the effects of changes in climatic variability in climate change scenarios on model predictions.

Most modelling studies investigating the impact of climate change on crop production considered only changes in the means of the climate variables. 
Changes in means, derived from GCMs, were applied to historical weather data to construct scenarios of climate change relevant to agricultural applications (e.g. Giorgi \& Mearns 1991, Kenny et al. 1993, Semenov et al. 1993). Recent work on the sensitivity of crop simulation models to changes in climate variables has clearly shown that changes in variability can have a significant effect on crop growth and associated agricultural risk (Nonhebel 1994, Semenov \& Porter 1994, 1995, Mearns et al. 1996, Wilks \& Riha 1996. Wolf et al. 1996). Extreme weather events, such as drought or cold spells, can have severe consequences for crops and the frequency of occurrence of such events has been shown to be better correlated with changes in the variability of climate variables than with changes in the mean values (Katz \& Brown 1992). Crop growth simulation models incorporate a mixture of non-linear responses of the crop to the climate. It is important that any assessments of the impact of climate change on agricultural production include changes in climatic variability as well as changes in means. One of the aims of our study was to assess model predictions of the effects of changes in climatic variability on crop yields and to investigate the consistency among the models. The methodology of development of climate change scenarios, incorporating changes in variability using the LARS-WG stochastic weather generator, is described by Barrow et al. (1996, this issue) and Semenov \& Barrow (1997).

\section{METHODOLOGY}

Five wheat models (AFRCWHEAT2, CERES, NWHEAT, SIRIUS and SOILN) were evaluated for climate change conditions. Model comparison in this study is based on the models' outputs. Explaining the differences in model results on the basis of their structure was considered too complicated and almost impossible due to the complex and varied structure of the models (see also Wolf et al. 1995, 1996).

To analyse the differences among the models and the implications for their use in climate change studies, the following procedure was applied. The models were first calibrated against field experiments (see Wolf et al. 1996). The calibrated models were then run for climate change scenarios derived from the GCMs. This showed the impact of climate change on wheat yields according to the different crop models and GCM scenarios. Analyses were conducted for 2 European sites, Rothamsted, United Kingdom, and Seville, Spain, which were considered representative of temperate and Mediterranean climate zones, respectively.

To evaluate the effect of changes in climatic variability on crop yields simulated by different wheat models,
2 sets of climate change scenarios were produced: 'climate scenarios' incorporated only monthly mean changes in weather variables; 'climate scenarios with changed variability' included changes in daily precipitation intensity, the duration of dry and wet spells, and the mean and variance of temperature. All scenarios were constructed for a time period of $30 \mathrm{yr}$ using the LARS-WG stochastic weather generator (Barrow \& Semenov 1995, Barrow et al, 1996). The 'baseline climate' was generated after calibration of LARS-WG for historical weather data at each site.

The climate change scenarios were constructed in the following way. The predictions of climate change, derived from the GCMs, were applied to the parameters of LARS-WG which was then used to generate the appropriate scenario. Two types of GCM experiments were used: equilibrium $2 \times \mathrm{CO}_{2}$ models, which calculate the change in climate with the equivalent of doubling of atmospheric $\mathrm{CO}_{2}$ and transient modcls, which calculate a continuous change in climate over time with a coupled ocean-atmosphere system. The GCM experiments used were those from the UK Meteorological Office low resolution and high resolution GCM equilibrium experiments (UKLO and UKHI, respectively) and the UK Meteorological Office and the Geophysical Fluid Dynamics Laboratory GCM transient experiments (UKTR and GFDL, respectively) (Barrow et al. 1996). For both UKHI and UKTR, scenarios were produced which included a change in climatic variability, UKHI (with var.) and UKTR (with var.); and those which did not, UKHI (no var.) and UKTR (no var.).

Calculations were performed using these scenarios and the corresponding increased concentrations of atmospheric $\mathrm{CO}_{2}$. For the equilibrium scenarios (UKLO and UKHI) the $\mathrm{CO}_{2}$ concentration was set at $560 \mathrm{ppm}$ (equivalent to a doubling of the pre-industrial $\mathrm{CO}_{2}$ concentration). For both transient experiments 2 decades were used: UKTR, decades $31-40$ and 66-75; and GFDL, decades 25-34 and 55-64. For each of these experiments, the scenarios for the first decade correspond to a global-mean temperature change of $+0.68^{\circ} \mathrm{C}$ and were applied in conjunction with an atmospheric $\mathrm{CO}_{2}$ concentration of $454 \mathrm{ppm}$. For the scenarios for the second decade the global-mean temperature change was $+1.76^{\circ} \mathrm{C}$ and the $\mathrm{CO}_{2}$ concentration was $617 \mathrm{ppm}$. The values for both variables were calculated using a simple climate model (MAGICC; Wigley 1994). This model provided internally consistent estimates of the course of global-mean $\mathrm{CO}_{2}$ concentration and temperature between 1990 and 2100 , based on scenarios of anthropogenic emissions of the various greenhouse gases and sulphur dioxide. In this study, the Intergovernmental Panel on Climate Change (IPCC) emissions scenario IS92a (Leggett et al. 1992) was used. 
Grain yield (GR, kg dry matter ha ${ }^{-1}$ ), its coefficient of variation $(\mathrm{CV})$ and cumulative probability functions were used to compare model results

\section{RESULTS}

Higher atmospheric $\mathrm{CO}_{2}$ concentration resulted in an increased $\mathrm{CO}_{2}$ assimilation rate and a nil to slight decrease in transpiration rate in most model runs (see Wolf et al. 1996). To analyse the impact of climate change, the models were run for climate scenarios with the corresponding increase in $\mathrm{CO}_{2}$ concentration (see above). Not all of the models were applied to all situations and sites. SOILN was run for the scenarios in Rothamsted and for potential production only. The other models were used for both sites. With CERES and NWHEAT both potential and water-limited crop yields were calculated, with AFRCWHEAT2 and SIRIUS only water-limited crop yields. Results shown are the means of 30 yr of simulations.

\subsection{Rothamsted: equilibrium scenarios}

Grain yield: (1) Potential production. The UKLO scenario resulted in lower grain yields in SOILN and NWHEAT, but not in CERES, than at present (Fig. 1). The UKHI (no var.) scenario resulted in higher grain yields in SOILN and NWHEAT than the UKLO results, but lower yields than at present (again except for CERES, which showed little change). With changed climatic variability in the UKHI (with var.) scenario (UKHIV in Fig. 1), this gave the same grain yields in CERES and SOILN and a lower grain yield in NWHEAT.

(2) Water-limited production. The UKLO scenario resulted in a lower grain yield in SIRIUS, the same grain yields in NWHEAT and AFRCWHEAT2 and a slightly higher grain yield in CERES, compared to grain yields at present. The UKHI (no var.) scenario resulted in higher values of grain yield in all runs than the UKLO results, and they were also higher than present values except for the yield in SIRIUS. Changed variability in the UKHI scenario gave a lower grain yield in NWHEAT, the same grain yields in CERES and AFRCWHEAT2, and a slightly higher grain yield in SIRIUS.

$C V$ of grain yield. For all GCM scenarios, the CVs of grain yield in the potential situation were slightly higher than the CVs at present in CERES and SOILN but remained the same in NWHEAT (Fig. 1). In the water-limited situation, the UKLO and UKHI (no var.) scenarios resulted in about the same $\mathrm{CV}$ of grain yield as CV at present, except in NWHEAT. With changed climate variability in the UKHI scenario, the CV of grain yield decreased in SIRIUS and AFRCWHEAT2, remained almost the same in NWHEAT and slightly increased in CERES water-limited runs.

\subsection{Rothamsted: transient scenarios}

\subsubsection{UKTR scenario}

Grain yield: (1) Potential production. The UKTR6675 (no var.) scenario (6675 indicates the decade 66-75) resulted in considerable increases in grain yield, with the smallest increase in NWHEAT (Fig. 2). Changed climatic variability did not change the grain yield in any models. For the UKTR3140 scenario, grain yield was identical to that at present in CERES and lower in SOILN and NWHEAT. The positive effect of $\mathrm{CO}_{2}$ enrichment was counterbalanced by the relatively low irradiation in the UKTR3140 scenario

(2) Water-limited production. The UKTR6675 (no var.) scenario resulted in considerable increases in grain yield compared to grain yields at present. Changed climatic variability in the UKTR6675 (with var.) scenario (UKTR6675V in Fig. 2) resulted in the same grain yields in SIRIUS and AFRCWHEAT2, a slightly lower grain yield in CERES, and a much lower grain yield in NWHEAT. For the UKTR3140 scenario, grain yield was the same as current grain yield in SIRIUS, slightly higher in CERES, and much higher in AFRCWHEAT2 and NWHEAT.

$C V$ of grain yield. The UKTR3140 and UKTR6675 (no var.) scenarios resulted in almost no change in the CVs of grain yield in the potential situations, compared to CVs at present (Fig. 2). The CVs did not increase in these runs with changed climate variability. Only in the SOILN run did the UKTR3140 scenario result in a moderately higher value for $\mathrm{CV}$ of grain yield. In the water-limited situation, the UKTR6675 (no var.) scenario resulted in about the same CV of grain yield as at present in CERES, slightly lower CV in AFRCWHEAT2 and SIRIUS, and a moderately lower CVs in NWHEAT. For the UKTR3140 scenario, the decreases in CV were similar or slightly more pronounced. The CV of grain yield under water limitation was much higher in NWHEAT than in the other models. With changed climatic variability in the UKTR6675 scenario, CV of grain yield increased slightly in all water-limited runs. The CVs of grain yield in Rothamsted were low and changed only slightly with climate, which indicates that water supply was almost non-limiting for crop growth. In NWHEAT, the CV of grain yield was higher than in the other models, with the lowest value in the UKTR3140 scenario climate and the highest values in 
(a) Grain yield
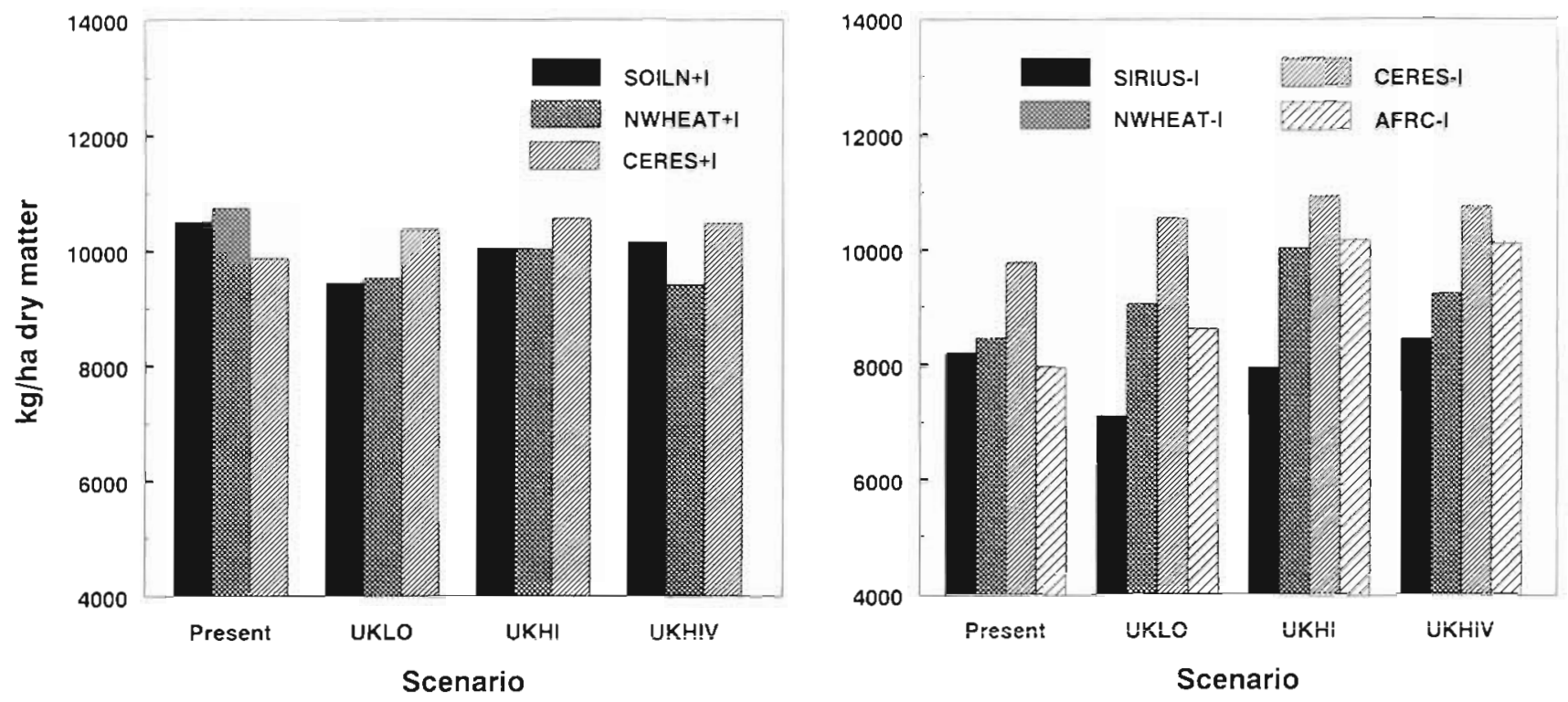

(b) CV of grain yield
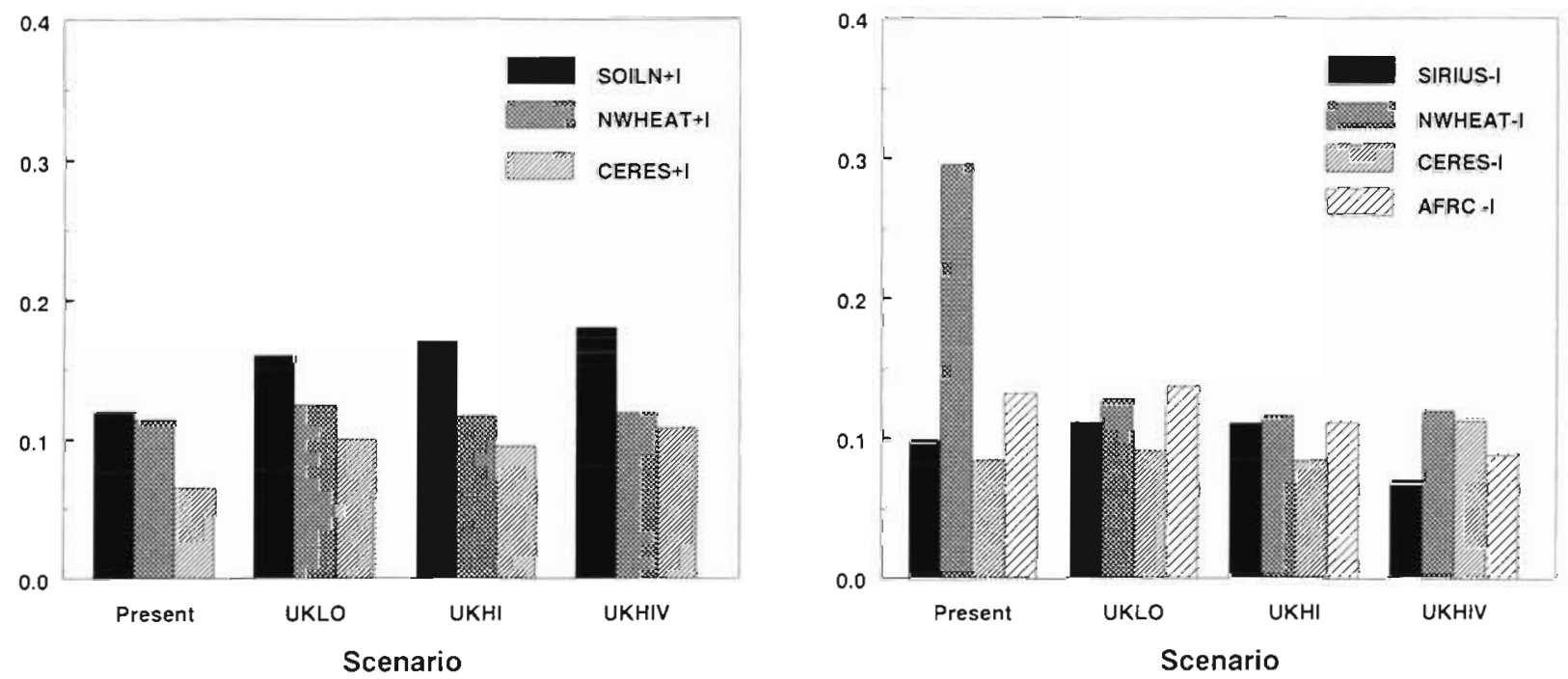

Fig. 1. (a) Grain yield of winter wheat and (b) its coefficient of variation, under present and future climate conditions in Rothamsted, UK, as simulated with the SOILN, SIRIUS, NWHEAT, CERES and AFRCWHEAT2 (AFRC) models for potential (+l) and water-limited (-I) production situations. Results refer to $30 \mathrm{yr}$ of generated weather data for baseline climate, for $2 \times \mathrm{CO}_{2}$ equilibrium UKLO and UKHI scenarios, and for the UKHI scenario with changed climatic variability (UKHIV)

the present (baseline) and UKTR6675 (with var.) scenario climates. This indicates the relatively high risk of yield reduction by water shortage in NWHEAT.

\subsubsection{GFDL scenario}

Grain yield. The GFDL2534 scenario resulted in slight decreases in grain yield in NWHEAT (potential) and SIRIUS, and slight and moderate increases in AFRCWHEAT2 and NWHEAT (water-limited), respectively. The GFDL5564 senario resulted in moderate increases in grain yield in the NWHEAT (potential), CERES (potential), SIRIUS and CERES (water-limited) runs, and strong increases in NWHEAT (water-limited) and AFRCWHEAT2 (Fig. 3).

$C V$ of grain yield. In the potential situation, the CVs of grain yield were the same or slightly lower 
(a) Grain yield
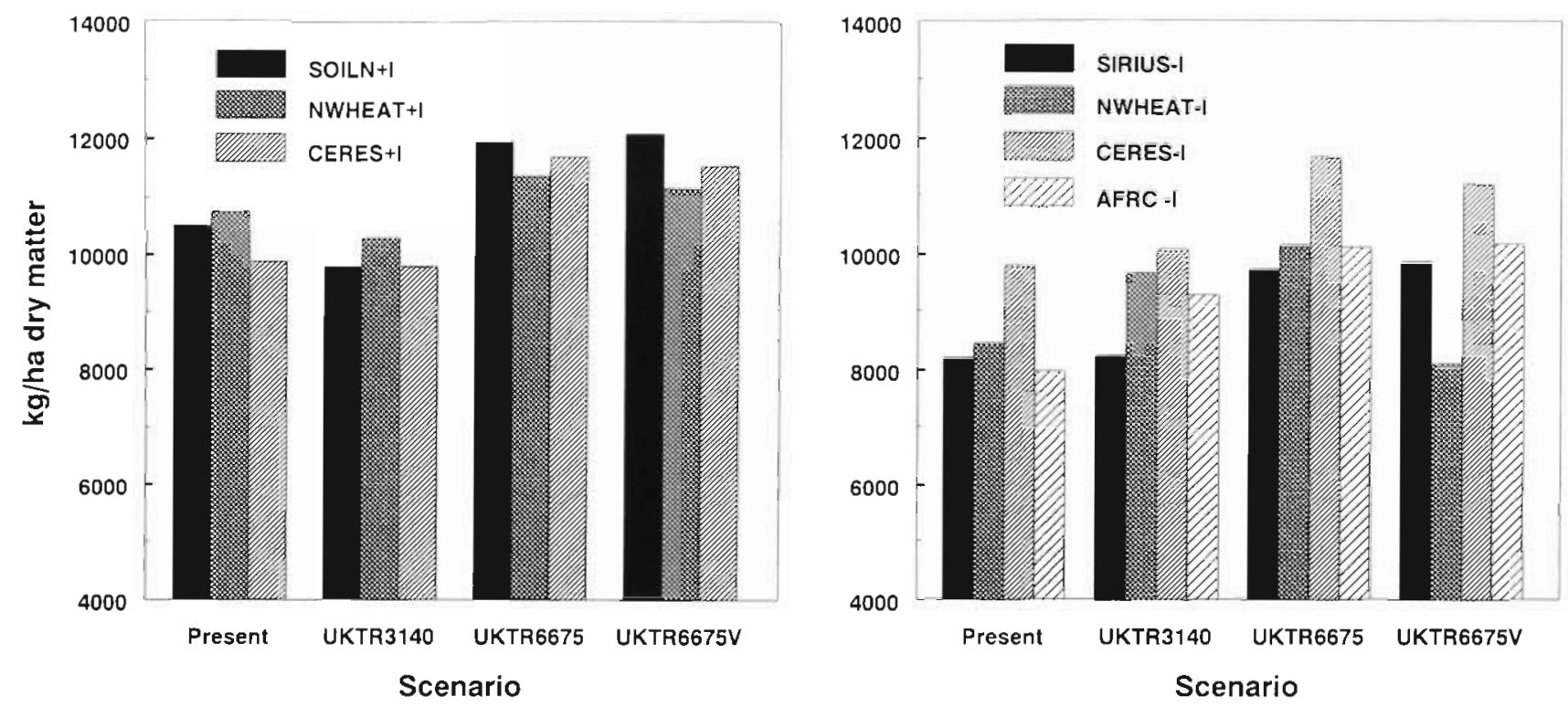

(b) CV of grain yield
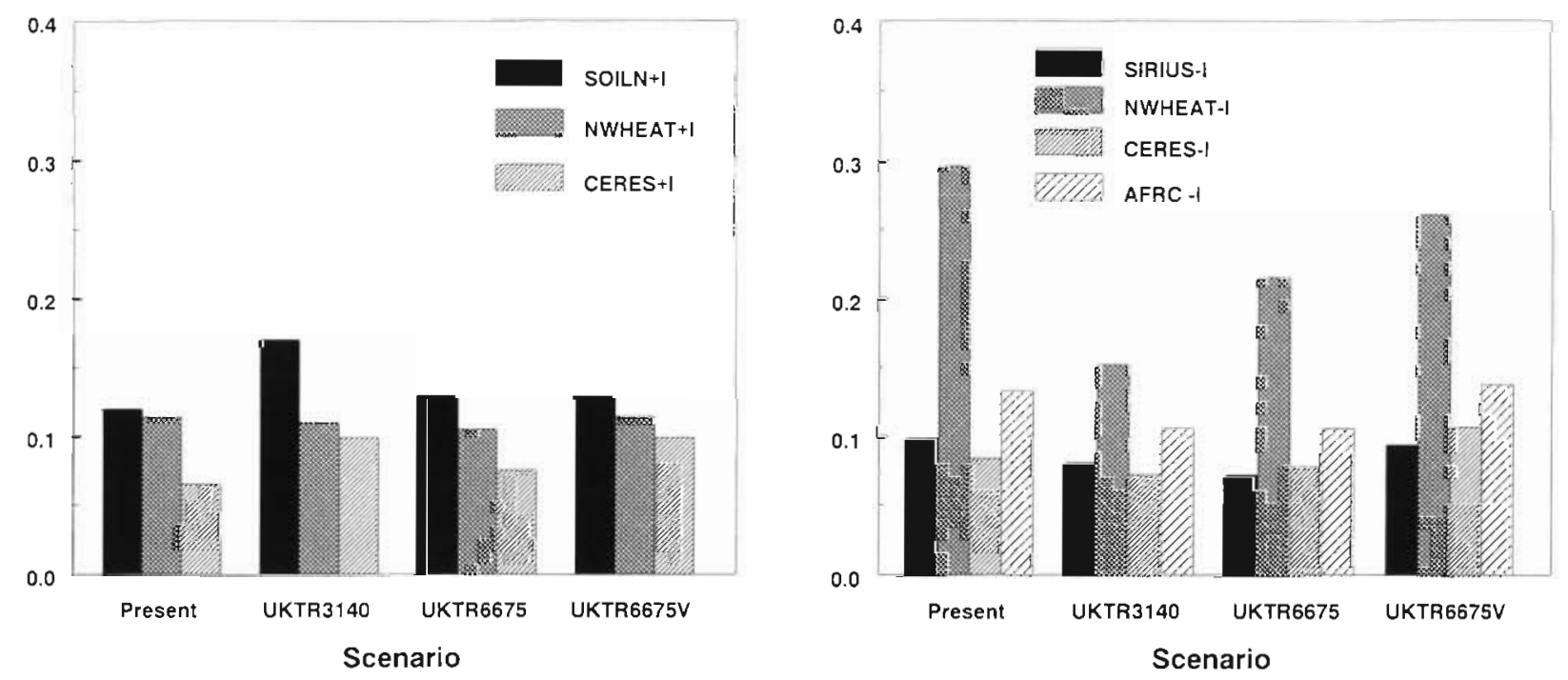

Fig. 2. (a) Grain yield of winter wheat and (b) its coefficient of variation, under present and future climate conditions in Rothamsted, UK as simulated with the SOILN, SIRIUS, NWHEAT, CERES and AFRCWHEAT2 (AFRC) models for potential (+I) and water-limited (-1) production situations. Results refer to 30 yr of generated weather data for baseline climate, for transient UKTR3140 and UKTR6675 scenarios, and for UKTR6675 scenario with changed climatic variability (UKTR6675V)

than those at present (Fig. 3). In the water-limited situation, the GFDL2534 scenario resulted in the same, slightly lower and much lower values for $\mathrm{CV}$ of grain yield in AFRCWHEAT2, SIRIUS and NWHEAT, respectively. The GFDL5564 scenario resulted in a slightly higher value for $\mathrm{CV}$ of grain yield in CERES, slightly lower values in AFRC. WHEAT2 and SIRIUS, and a much lower value in NWHEAT.

\subsection{Seville: equilibrium scenarios}

Grain yield: (1) Potential production. The UKLO scenario resulted in lower grain yield in NWHEAT, and little change in CERES, compared to grain yields at present (Fig. 4). In both UKHI scenarios (with and without changed variability), there was little change in grain yields in NWHEAT, compared to the UKLO results. 
(a) Grain yield
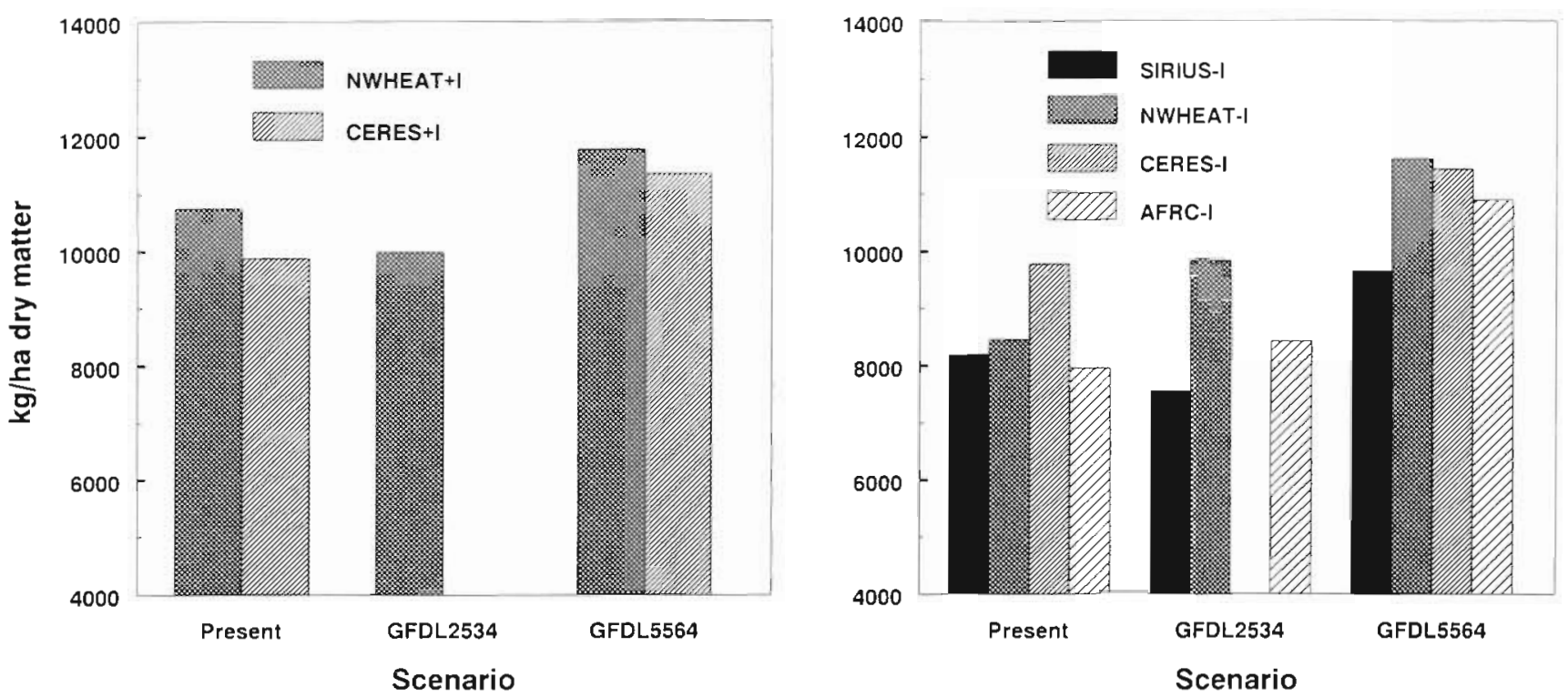

(b) CV of grain yield
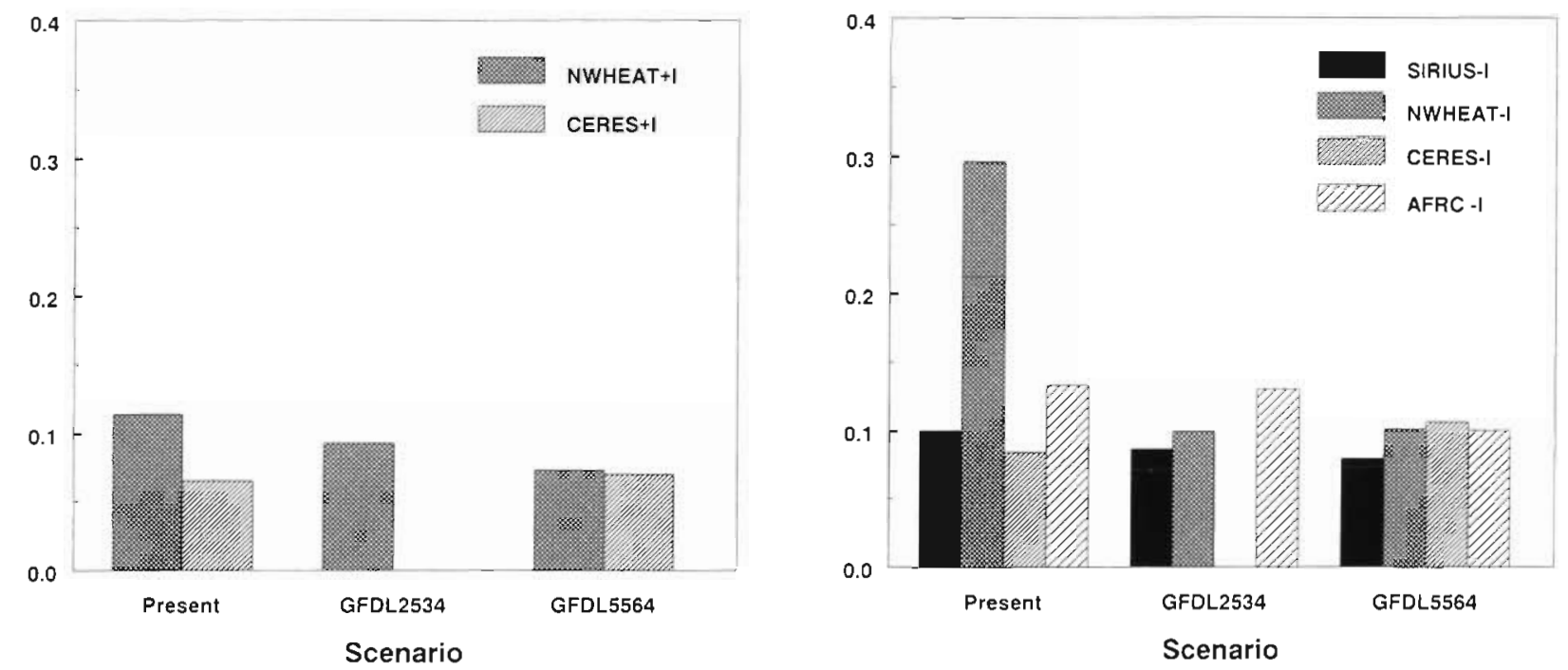

Fig. 3. (a) Grain yield of winter wheat and (b) its coefficient of variation, under present and future climate conditions in Rothamsted, UK, as simulated with the SIRIUS, NWHEAT, CERES and AFRCWHEAT2 (AFRC) models for potential (+I) and water-limited $(-1)$ production situations. Results refer to $30 \mathrm{yr}$ of generated weather data for baseline climate and for transient GFDL2534 and GFDL5564 scenarios

(2) Water-limited production. The UKLO scenario resulted in similar values for grain yield in NWHEAT and SIRIUS, a slightly higher value in CERES and a slightly lower value in AFRCWHEAT2, all compared to grain yields at present (Fig. 4). The UKHI (no var.) scenario resulted in very low grain yields in the SIRIUS and NWHEAT runs, and a moderately lower grain yield in the AFRCWHEAT2 run, compared to UKLO results and also compared to grain yields at present. Changed climatic variability in the UKHI (with var.) scenario
(UKHIV in Fig. 4) resulted in almost no change in the grain yields compared with UKHI (no var.).

$C V$ of grain yield. There was little change in the CVs in the potential production situation, compared to present values (Fig. 4). In the water-limited situation, the UKLO scenario resulted in CVs of grain yield that were similar to present values in AFRCWHEAT2 and NWHEAT, lower in SIRIUS and higher in CERES (Fig. 4). The UKHI (no var.) scenario resulted in about the same CV of grain yield in AFRCWHEAT2 and a 
(a) Grain yield

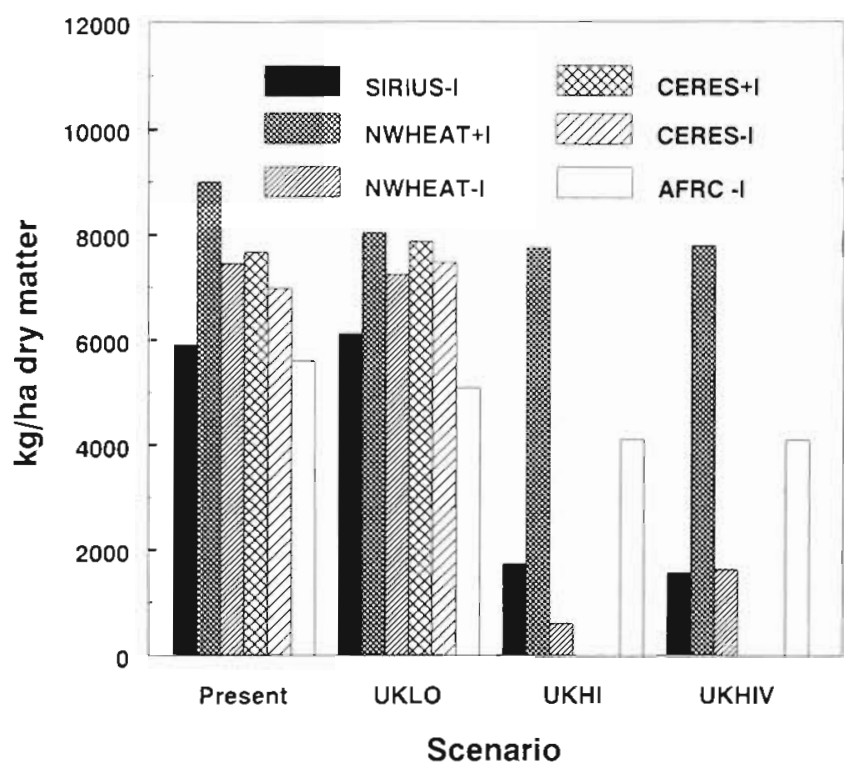

(b) CV of grain yield

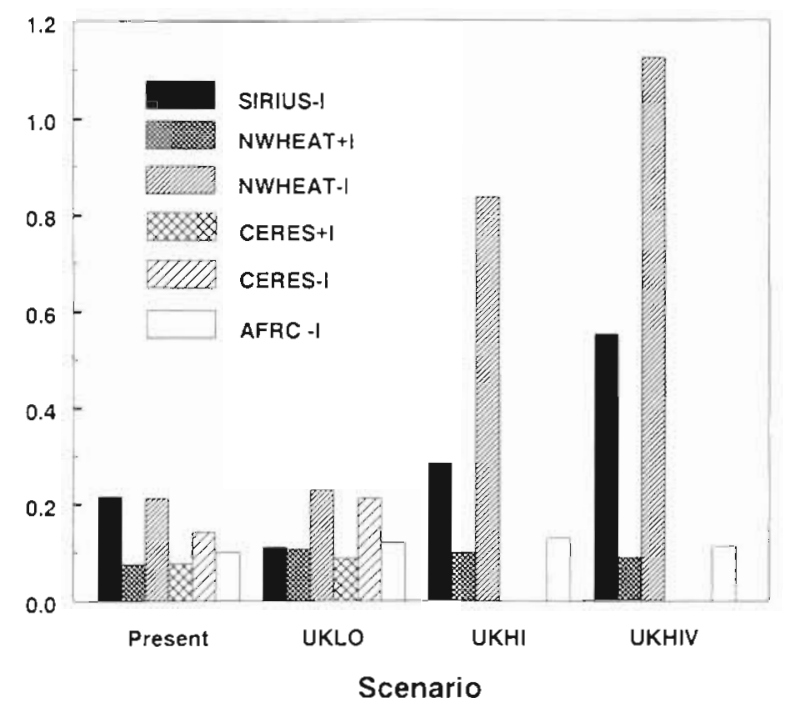

Fig. 4. (a) Grain yıeld of wheat and (b) its coefficient of variation, under present and future climate conditions in Seville, Spain, as simulated with the SIRIUS, NWHEAT, CERES and AFRCWHEAT2 (AFRC) models for potential (+I) and waterlimited (-I) production situations. Results refer to $30 \mathrm{yr}$ of generated weather data for baseline climate, for $2 \times \mathrm{CO}_{2}$ equilibrium. UKLO and UKHI scenarios, and for the UKHI scenario with changed climatic variability (UKHIV)

moderately and much higher $\mathrm{CV}$ in SIRIUS and NWHEAT, respectively, compared to UKLO results and also compared to CVs at present. Under changed climatic variability in the UKHI (with var.) scenario, the $\mathrm{CV}$ of grain yield remained the same in AFRCWHEAT2 and increased strongly in SIRIUS and NWHEAT.

\subsection{Seville: transient scenarios}

\subsubsection{UKTR scenario}

Grain yield: (1) Potential production. The UKTR6675 (no var.) scenario resulted in slight and moderate increases in grain yield in CERES and NWHEAT, respectively, compared to present values (Fig. 5). Changed climatic variability in the UKTR6675 scenario (UKTR6675V in Fig. 5) hardly changed the grain yields in either model. In the UKTR3140 scenario, the grain yield in CERES was similar to the present value and that in NWHEAT was slightly higher.

(2) Water-limited production. The UKTR6675 (no var.) scenario resulted in a slight decrease and a slight increase in grain yield in SIRIUS and NWHEAT, respectively, compared to grain yields at present (Fig. 5). Changed climatic variability in the UKTR6675 scenario resulted in moderately and considerably lower grain yields in SIRIUS and NWHEAT, respectively. For the UKTR3140 scenario grain yields from all models were about the same as grain yields at present.

$C V$ of grain yield. There was little change in the CVs of grain yield in the potential production situation for all the scenarios (Fig. 5b). In the water-limited situation, the UKTR6675 (no var.) scenario resulted in almost the same CVs of grain yield in SIRIUS and AFRCWHEAT2 as present values, a slightly lower CV in CERES, and a moderately higher CV in NWHEAT (Fig. 5). The UKTR3140 scenario resulted in higher CVs of grain yield in SIRIUS and NWHEAT, and no change in the CVs in CERES and AFRCWHEAT2, compared to present values. With changed climatic variability in the UKTR6675 scenario, the CV of grain yield remain constant in AFRCWHEAT2 and increased strongly in the other model runs:

The UKTR6675 (no var.) scenario resulted in slightly higher (CERES, AFRCWHEAT and NWHEAT) or lower (SIRIUS) values for grain yield and nil to moderately higher values for CV of grain yield in the waterlimited runs (Fig. 5). Incorporation of changes in climatic variability in the UKTR6675 scenario resulted in much lower grain yields (except AFRCWHEAT) and much higher CVs. Changing variability in climate change scenarios should not affect monthly means such as monthly total precipitation or monthly mean maximum temperature. These monthly means were compared for the UKTR6675 scenarios with and without changes in variability at Seville (Table 1). They showed no significant difference between monthly mean maximum temperatures. Precipitation totals were statistically different for 8 individual months, however the difference in total precipitation over the period of wheat growth was small (e.g. from January up to the end of July; see Table 2). The UKTR6675 (no 
(a) Grain yield

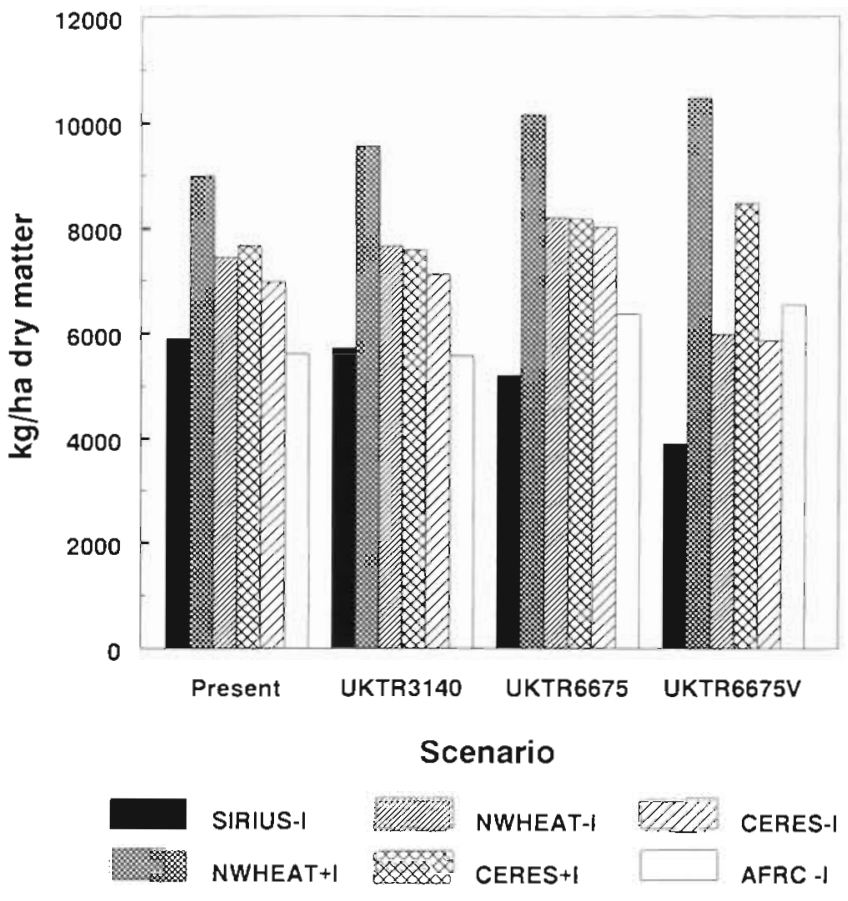

(b) $\mathrm{CV}$ of grain yield

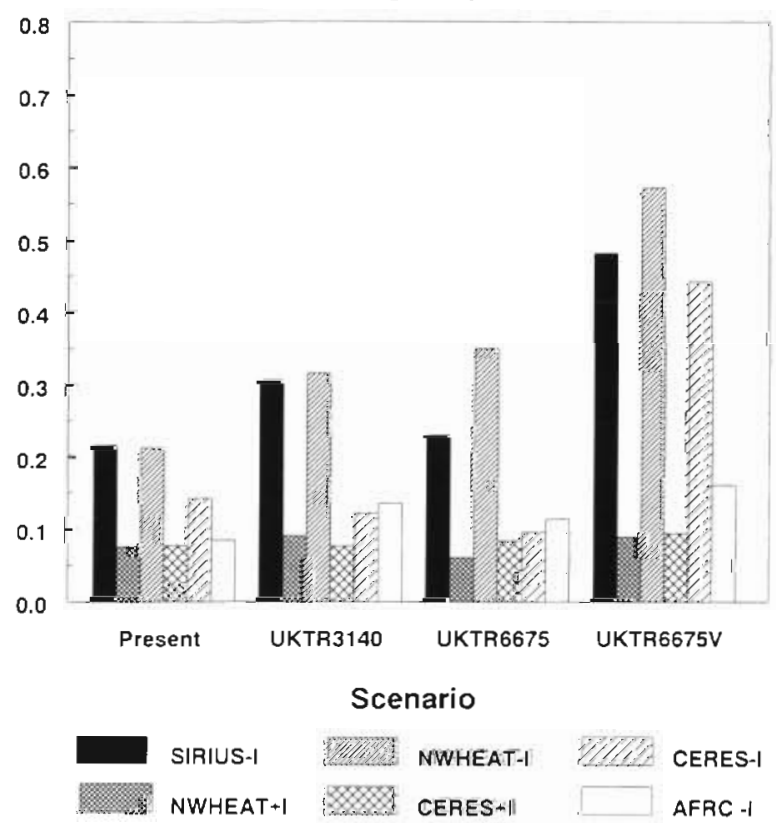

Fig. 5. (a) Grain yield of wheat and (b) its coefficient of variation, under present and future climate conditions in Seville, Spain, as simulated with the SIRIUS, NWHEAT. CERES and AFRCWHEAT2 (AFRC) models for potential (+I) and waterlimited (-I) production situations. Results refer to $30 \mathrm{yr}$ of generated weather data for baseline climate, for transient UKTR3140 and UKTR6675 scenarios, and for the UKTR6675 scenario with changed climatic variability (UKTR6675V)
Table 1. Mean monthly values of total precipitation (m.m) and maximum temperature $\left({ }^{\circ} \mathrm{C}\right)$ at Seville, Spain, for the UKTR6675 scenarios with and without a change in variability Values marked with an asterisk indicate where the null hypothesis of equal monthly means was rejected

\begin{tabular}{|c|c|c|c|c|}
\hline & \multicolumn{2}{|c|}{ Without variability } & \multicolumn{2}{|c|}{ With variability } \\
\hline & Precip. & Temp. & Precip. & Temp. \\
\hline Jan & 55.5 & 12.0 & $34.4^{\circ}$ & 11.9 \\
\hline Feb & 64.5 & 15.5 & 60.6 & 15.6 \\
\hline Mar & 34.6 & 15.6 & 23.7 & 15.7 \\
\hline Apr & 40.6 & 17.0 & 38.4 & 17.3 \\
\hline May & 7.8 & 21.7 & $15.0^{\circ}$ & 21.9 \\
\hline Jun & 7.5 & 28.6 & $3.0^{\circ}$ & 28.0 \\
\hline JuI & 0.0 & 31.6 & $9.2^{\circ}$ & 31.5 \\
\hline Aug & 2.3 & 32.5 & $0.3^{*}$ & 32.5 \\
\hline Sep & 3.5 & 31.2 & $0.7^{*}$ & 31.6 \\
\hline Oct & 48.8 & 24.0 & 30.3 & 24.4 \\
\hline Nov & 23.6 & 17.2 & $3.5^{\circ}$ & 16.9 \\
\hline Dec & 43.1 & 12.2 & $20.4^{*}$ & 12.0 \\
\hline
\end{tabular}

Table 2. Effect of climate change and a change in climate variability on wheat yield $\left(1000 \mathrm{~kg}\right.$ dry matter ha $\left.{ }^{-1}\right)$ and on its coefficient of variation (CV) in Seville, Spain, as simulated with SIRIUS and NWHEAT for the UKTR6675 scenario. Total precipitation (mm) and cumulative mean temperature $\left({ }^{\circ} \mathrm{C}\right)$ were calculated for the period from January up to the end of July

\begin{tabular}{|cccc|}
\hline & Base & UKTR & UKTR with var. \\
\hline SIRIUS & & & \\
Grain yield & 5.6 & 5.2 & 3.9 \\
CV of yield & 0.24 & 0.23 & 0.48 \\
NWHEAT & & & \\
Grain yield & 7.4 & 8.2 & 6.0 \\
CV of yield & 0.21 & 0.35 & 0.57 \\
Total precip. & 296 & 210 & 184 \\
Cumul temp. & 3630 & 4293 & 4323 \\
\hline
\end{tabular}

var.) scenario for Seville resulted in almost no changes in grain yield or its $\mathrm{CV}$ in SIRIUS. When changed climatic variability was included, the results were dramatically different: grain yield considerably decreased and CV strongly increased. As indicated above, this is the result of a different partitioning of precipitation over the growth period, leading to prolonged dry spells. In SIRIUS, the probability of producing yields less than $3.5 \mathrm{tha}^{-1}$ was almost $50 \%$ for the UKTR6675 (with var.) scenario, whereas it was only about $10 \%$ for the UKTR6675 (no var.) scenario or the baseline climate (Fig. 6). The same occurs in NWHEAT Such a high probability of low grain yields indicates that the region around Seville may become unsuitable for wheat production under this climate change scenario. 

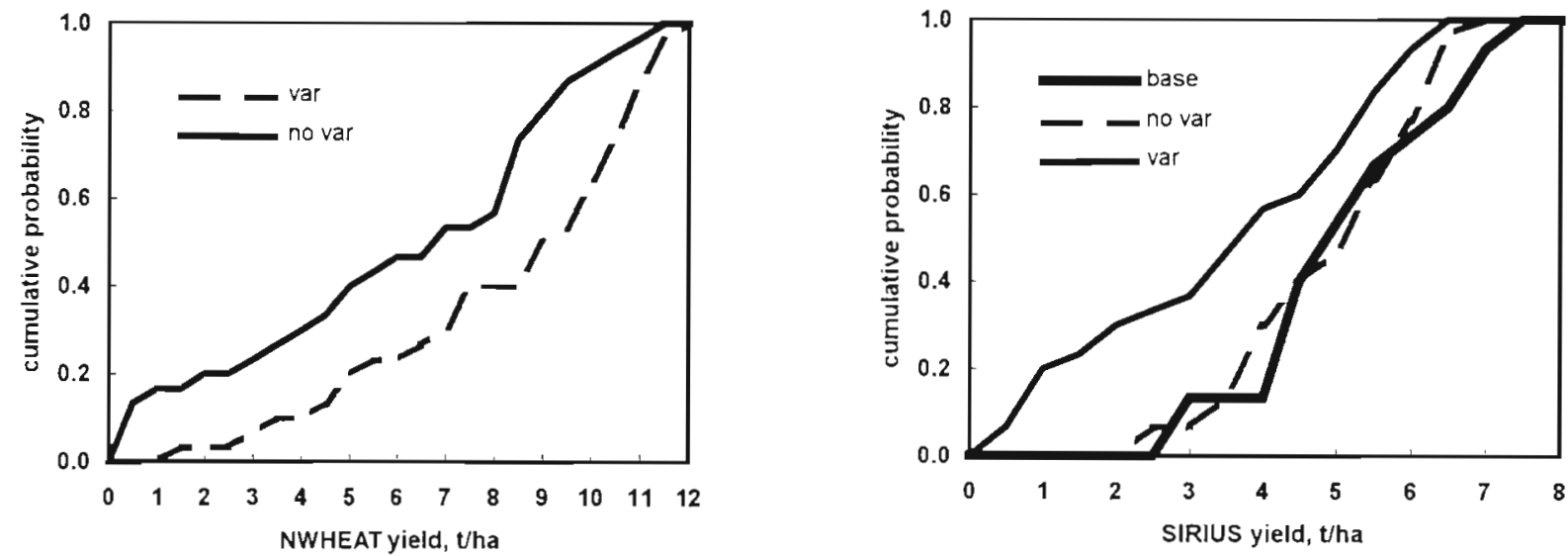

Fig. 6. Cumulative probability function for grain yield of wheat under future climate conditions in Seville, Spain, as simulated with the NWHEAT and SIRIUS models for the water-limited production situation. Results refer to 30 yr of generated weather data for transient UKTR6675 scenarios both with and without changed climatic variability

(a) Grain yield

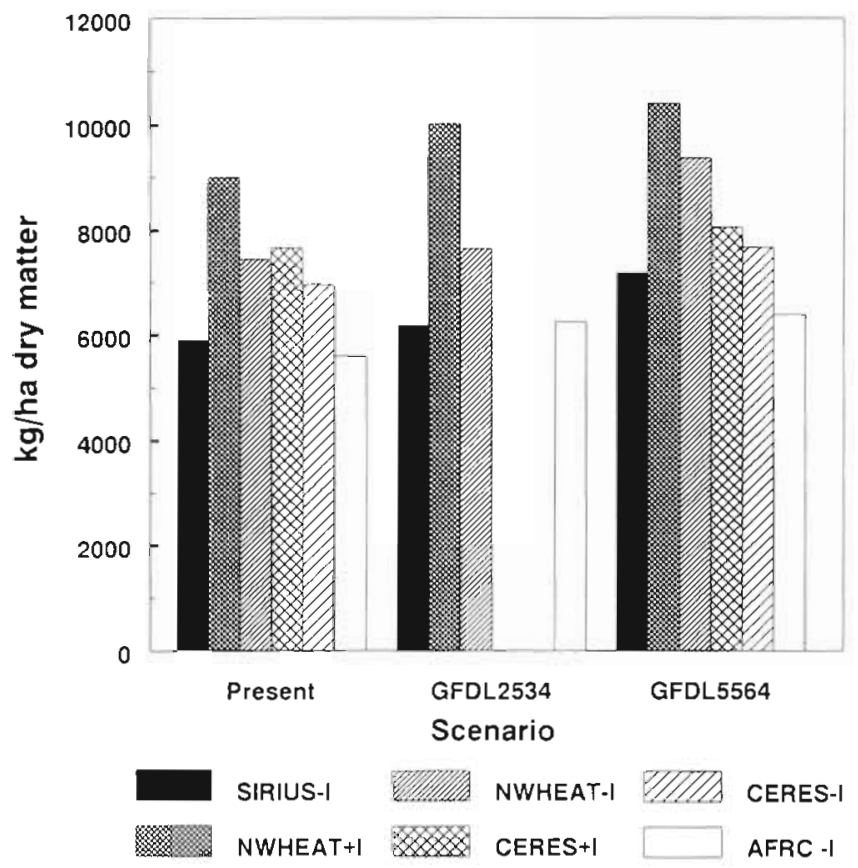

(b) $\mathrm{CV}$ of grain yield

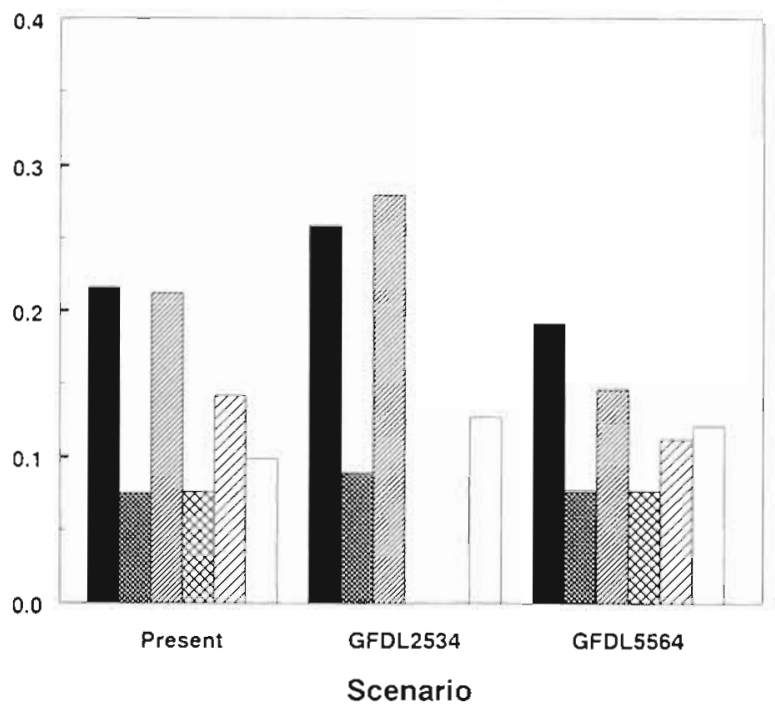

SIRIUS-I

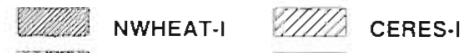
CERES+1 $\square$ AFRC -

Fig. 7 (a) Grain yield of wheat and (b) its coefficient of variation, under present and future climate conditions) in Seville, Spain, as simulated with the SIRIUS, NWHEAT, CERES and AFRCWHEAT2 (AFRC) models for potential (+I) and water-limited (-l) production situations. Results refer to 30 yг of generated weather data for baseline climate and for transient GFDL2534 and GFDL5564 scenarios

\subsubsection{GFDL scenario}

Grain yield. The GFDL2534 scenario resulted in about the same grain yields in SIRIUS and NWHEAT (water-limited) and slight and moderate increases in yield in AFRCWHEAT2 and NWHEAT (potential), respectively, compared to present values (Fig. 7a). The GFDL5564 scenario resulted in slight increases in grain yield in AFRCWHEAT2 and CERES, and moderate increases in SIRIUS and NWHEAT, all compared with grain yields at present. The grain yields in NWHEAT were relatively high and those in SIRIUS and AFRCWHEAT2 were relatively low.

$C V$ of grain yield. For the GFDL2534 scenario, the values of $\mathrm{CV}$ of grain yield compared with present values were slightly higher in NWHEAT (potential) and 
AFRCWHEAT2, and moderately higher in SIRIUS and NWHEAT (water-limited). With the GFDL5564 scenario, the CV was slightly higher in AFRCWHEAT2, remained the same in CERES and NWHEAT (potential), was slightly lower in SIRIUS and CERES (waterlimited), and was moderately lower in NWHEAT (water-limited), all compared with present values of CV of grain yield (Fig. $7 \mathrm{~b}$ ).

\section{CONCLUSIONS}

A summary of the results from the 5 wheat models and various GCM scenarios is given in Table 3 and shows that in most cases the models predicted similar grain yield and CV of grain yield. Climate change scenarios were constructed for various $2 \times \mathrm{CO}_{2}$ equilibrium and transient GCM experiments. The range of GCMs used in this study reflects the evolution of climate change scenarios over the last decade. Comparison of the predicted impacts of climate change from different GCMs must account for the differences in the spatial patterns of climate change over Europe and the global mean temperature increases between the different GCM scenarios. For example, the UKLO, UKHI and UKTR6675 scenarios predicted a rise of 5.5, 4.6 and $2.1^{\circ} \mathrm{C}$, respectively, for Rothamsted. The $\mathrm{CO}_{2}$ concentration, according to IPCC estimates (Barrow et al. 1996), also differs (560 ppm in the equilibrium scenarios and $617 \mathrm{ppm}$ in the UKTR6675 scenario). These factors led to differences in grain yield prediction. For example, in comparison with the changes in grain
yieId for the UKTR6675 (no var.) scenario, which were strongly positive at Rothamsted and almost neutral at Seville, the effects of the UKLO and UKHI scenarios on grain yield were less positive or more negative. The transient GCM experiment (GFDL and UKTR) scenarios were comparable because the global mean temperature changes and $\mathrm{CO}_{2}$ concentrations were identical. As a result, model predictions were similar for both of the transient GCM runs. At Rothamsted the scenarios for the first decade had much lower irradiation than at present or in the scenario for the second decade, which resulted in lower grain yields. When the results from the wheat models were very different, most differences could be explained on the basis of model sensitivity to climate and differences in initial conditions. For example, different values used for initial and maximum amounts of available soil water in the various crop models changed the sensitivity to water shortage for the years with low rainfall.

The importance of changes in climatic variability was demonstrated by all of the wheat models. The predicted wheat yields and CVs were very different in some of the European locations for scenarios with and without changed variability. This will affect any conclusion drawn about wheat suitability in certain European regions under climate change. For example, the UKTR6675 scenario with only mean climate changes resulted in large increases in grain yield for Rothamsted and nil to small increases for Seville, with almost no change in the values of the yield CV. However, with changes in variability this scenario resulted in nil to large decreases in grain yield for Rothamsted, and sub-

Table 3. Summary of the sensitivity of wheat grain yield to changes in climate $(+, 0,-$ : positive, nil, negative effect of climate change on grain yield; ?: no simulation result) as based on the equilibrium and transient scenarios, both with and without changes in climatic variability. Results are based on simulation runs with the different wheat models for both potential (+I) and water-limited production situations (-1) at Rothamsted, UK, and Seville, Spain. For information on the scenarios see the section 'Methodology' Simulations were done for each climate scenario with the corresponding increased level of atmospheric $\mathrm{CO}_{2}$

\begin{tabular}{|c|c|c|c|c|c|c|c|}
\hline \multirow[t]{2}{*}{ Site and scenario } & \multirow{2}{*}{$\begin{array}{c}\text { AFRCWHEAT2 } \\
-I\end{array}$} & \multicolumn{2}{|c|}{ CERES } & \multicolumn{2}{|c|}{ NWHEAT } & \multirow{2}{*}{$\begin{array}{c}\text { SIRIUS } \\
-I\end{array}$} & \multirow{2}{*}{$\begin{array}{c}\text { SOILN } \\
+\mathrm{I}\end{array}$} \\
\hline & & $+\mathrm{I}$ & $-I$ & +1 & $-\mathrm{I}$ & & \\
\hline \multicolumn{8}{|l|}{ Rothamsted } \\
\hline UKLO (no var.) & 0 & 0 & 0 & - & 0 & - & - \\
\hline UKHI (no var.) & + & 0 & + & - & + & - & - \\
\hline UKHI (var.) & + & 0 & 0 & - & 0 & 0 & - \\
\hline UKTR6675 (no var.) & + & + & + & + & + & + & + \\
\hline UKTR6675 (var.) & + & + & + & 0 & 0 & + & + \\
\hline GFDL5564 (no var.) & + & + & + & + & + & + & $?$ \\
\hline \multicolumn{8}{|l|}{ Seville } \\
\hline UKLO (no var.) & - & 0 & + & - & 0 & 0 & $?$ \\
\hline UKHI (no var.) & - & $?$ & $?$ & - & - & - & $?$ \\
\hline UKHI (var.) & - & $?$ & $?$ & - & - & - & $?$ \\
\hline UKTR6675 (no var.) & + & + & + & + & + & 0 & $?$ \\
\hline UKTR6675 (var.) & + & + & - & + & - & - & $?$ \\
\hline GFDL5564 (no var.) & + & 0 & + & + & + & + & $?$ \\
\hline
\end{tabular}


stantial yield decreases for Seville, with strong increases in the yield CV under water-limited conditions. Such changes in climatic variability, which result in both a large decrease in average grain yield and a large increase in yield variability and thus a high agricultural risk, would make the region around Seville unsuitable for wheat production.

Acknowledgements. Many thanks are due to E. M. Barrow (Climate Research Unit, UK) for providing the climate change scenarios, Prof. J. R. Porter (Royal Veterinary and Agricultural University, Denmark) for his help with the AFRCWHEAT2 model and Dr P. D. Jamieson (Crop \& Food Research, New Zealand) for his assistance with the SIRIUS model. We are also indebted to 2 referees for their valuable reviews. This work was funded by the Commission of the European Communities' Environment Programme (Contract EV5V-CT930294). IACR receives grant-aided support from Biotechnology and Biological Science Research Council of the UK.

\section{LITERATURE CITED}

Barrow EM, Hulme M, Semenov MA (1996) Effect of using different methods in the construction of climate change scenarios: examples from Europe. Clim Res 7:195-211

Barrow EM, Semenov MA (1995) Climate change scenarios with high temporal and spatial resolution for agricultural applications. Forestry 68:349-360

Eckersten H, Jansson PE (1991) Modelling water flow, nitrogen uptake and production for wheat. Fertilis Res 27 : 313-329

Eckersten H, Jansson PE, Johnsson H (1994) SOILN model version 8.0. User's manual. Communications, 94, 4. Section of Hydrotechnics, Department of Soil Sciences, Swedish University of Agricultural Sciences, Uppsala

Giorgi F, Mearns LO (1991) Approaches to the simulation of regional climate change: a review. Rev Geophys 29: $191-216$

Godwin D, Ritchie J, Singh U, Hunt L (1990) A user's guide to CERES-Wheat-V2.10. International Fertilizer Development Center, Simulation Manual IFDC-SM-2, Muscle Shoals, AL

Groot JJR (1987) Simulation of nitrogen balance in a system of winter wheat and soil. Simulation reports CABO-TT no. 13. Centre for Agrobiological Research and Dept of Theoretical Production Ecology, Agricultural University, Wageningen

Groot JJR (1993) NWHEAT; nitrogen balance in a system of winter wheat and soil. In: Engel $T$, Klöcking B. Priesack E \& Schaaf $T$ (eds) Simulationsmodelle zur Stickstoffdynamik, Analyse und Vergleich. Agrarinformatik, Band 25 , Ulmer, Stuttgart p 397-411

Jamieson PD, Semenov MA, Brooking IR, Francis GS (in press) Sirius: a mechanistic model of wheat response to environmental variation. Field Crops Res

Jamieson PD. Wilson DR (1988) Agronomic uses of a model of wheat growth, development and water use. Proc Agron Soc NZ 18:7-10

Johnsson H, Bergström L, Jansson PE, Paustrian K (1987) Simulation of nitrogen dynamics and losses in a layered agri-

Editor: G. Esser, Gießen, Germany cultural soil. Agricult Ecosys Environ 18:333-356

Katz RW, Brown BG (1992) Extreme events in a changing climate: variability is more important than averages. Clim Change 21:289-302

Kenny GJ, Harrison PA, Parry ML (eds) (1993) EPOCH project: the effect of climate change on agricultural and horticultural potential in Europe. Research Report no. 2, Environmental Change Unit, University of Oxford

Leggett J, Pepper WJ, Swart RJ (1992) Emission scenarios for the IPCC: an update. In: Houghton JT, Callander BA, Varney SK (eds) Climate change 1992: the supplementary report to the IPCC scientific assessment. Cambridge University Press, Cambridge, p 69-96

Mearns LO, Rosenzweig C, Goldberg R (1996) The effects of changes in daily and interannual climatic variability on CERES-Wheat: a sensitivity study. Clim Change 32 : $257-299$

Nonhebel S (1994) The effects of use of average instead of daily weather data in crop growth simulation models. Agricult Sys 44:377-396

Porter JR (1984) A model of canopy development in winter wheat. J Agricult Sci (Cambridge) 102:383-392

Porter JR (1993) AFRCWHEAT2: a model of the growth and development of wheat incorporating responses to water and nitrogen. Eur J Agron 2:69-82

Ritchie J, Otter S (1985) Description of and performance of CERES-Wheat: a user-oriented wheat yield model. In: Willis WO (ed) ARS wheat yield project. Department of Agriculture, Agricultural Research Service, ARS-38, Washington DC, p 159-175

Semenov MA, Barrow EM (1997) Use of a stochastic weather generator in the development of climate change scenarios. Clim Change (in press)

Semenov MA, Porter JR (1994) The implications and importance of non-linear responses in modelling of growth and development of wheat. In: Grasman J, van Straten G (eds) Predictability and non-linear modelling in natural sciences and economics. Kluwer, Dordrecht, p 157-172

Semenov MA, Porter JR (1995) Climatic variability and the modelling of crop yields. Agricult For Meteorol 73:265-283

Semenov MA, Porter JR, Delecolle R (1993) Climatic change and the growth and development of wheat in the UK and France. Eur J Agron 2:293-304

Weir AH, Bragg PL, Porter JR, Rayner JH (1984) A winter wheat crop simulation model without water or nutrient limitations. J Agricult Sci (Cambridge) 102:371-382

Wigley TML (1994) MAGICC (model for the assessment of greenhouse-gas induced climate change). User's guide and scientific reference manual. University of East Anglia, Norwich

Wilks DS, Riha SJ (1996) High-frequency climatic variability and crop yields. Clim Change 32:231-235

Wolf J, Evans LG, Semenov MA, Eckersten H, Iglesias A (1996) Comparison of wheat simulation models under climate change. I Model calibration and sensitivity analyses. Clim Res 7:253-270

Wolf J, Semenov MA, Evans LG, Eckersten H, Iglesias A, Porter JR (1995) Effects on winter wheat: a comparison of five models. In: Harrison PA, Butterfield RE, Downing TE (eds) Climate change and agriculture in Europe: assessment of impacts and adaptations. Research Report 9, Environmental Change Unit, Oxford, p 231-280

Manuscript first received: February 28, 1996

Revised version accepted: July 9, 1996 